\title{
Melanoma biomarkers: Vox clamantis in deserto (Review)
}

\author{
MAYS AL-SHAER ${ }^{1}$, DIVYA GOLLAPUDI $^{2}$ and CHRIS PAPAGEORGIO ${ }^{3}$ \\ ${ }^{1}$ Department of Internal Medicine, University of Missouri, Columbia, MO 65203; \\ ${ }^{2}$ University of Missouri Medical School, MA215 Medical Sciences Building, Columbia, MO 65212; \\ ${ }^{3}$ Ellis Fischel Cancer Center, University of Missouri, Columbia, MO 65203, USA
}

Received January 25, 2010; Accepted March 18, 2010

DOI: 10.3892/ol_00000070

\begin{abstract}
Detecting malignant melanoma at an early stage, monitoring therapy, predicting recurrence and identifying patients at risk for metastasis continue to be a challenging and demanding objective. The last two decades have witnessed innovations in the field of melanoma biomarkers. However, global agreement concerning monitoring and early detection has yet to be reached. This is a review of the current literature regarding melanoma biomarkers including demographic, clinical, pathological and molecular biomarkers that are produced by melanoma or non-melanoma cells. A number of these biomarkers demonstrate promising results as possible methods for early detection, predicting recurrence and monitoring therapy. Other biomarkers appear to be promising for identifying patients at risk for metastasis. We reviewed the most pertinent information in the field thus far and how this knowledge can impact, or not, the management of melanoma patients prognostically and therapeutically.
\end{abstract}

\section{Contents}

1. Introduction

2. Demographic and clinical factors

3. Primary tumor characteristics

4. Serological factors

5. Circulating tumor cells

6. Current practice

7. Conclusion

\section{Introduction}

According to the National Institute of Health (NIH) definition, a biomarker is 'a characteristic that is objectively measured and

Correspondence to: Dr Chris Papageorgio, University of Missouri, Ellis Fischel Cancer Center, 1 Hospital Drive, Columbia, MO 65203, USA

E-mail: papageorgioc@health.missouri.edu

Key words: melanoma, malignant, biomarkers, early detection, monitoring therapy, predicting recurrence, metastasis risk, review of current literature evaluated as an indicator of normal biologic processes, pathogenic processes or pharmacologic responses to therapeutic intervention' (1). Tumor biomarkers can be clinical or statistical features, pathological findings or molecular markers that are produced by tumor or non-tumor cells (such as immune cells) (2). The detection of tumor markers has significant prognostic implications for a number of solid tumors, such as breast, prostate, ovarian and testicular. Malignant melanoma is trailing behind in spite of the discoveries achieved in the last decade. Lactate dehydrogenase (LDH) is the only molecular biomarker used in the current staging system (3), although it has low sensitivity and specificity (4). The prognosis of stage I and II melanoma according to the current staging system developed by the American Joint Committee on Cancer (AJCC) classification depends on the thickness of the lesion (3) as well as the presence of microscopic or macroscopic melanoma cells in the lymph nodes (4). The presence of such cells upstages the melanoma to stage III. For stage III and IV melanomas, the outcome is variable and the determination of prognostic factors is more difficult. No single biomarker has yet been identified that can determine the prognosis of these patients. Thus, at the present time, various biomarkers are used in an attempt to estimate the risk of recurrence. These indicators include demographic and clinical factors (5), primary tumor characteristics and pathological features (3), in addition to novel molecular biomarkers. Recurrent melanoma may be amenable to surgical resection if detected early, but there is no agreement regarding monitoring and early detection. Chest $\mathrm{X}$-ray, computed tomography, positron emission tomography and magnetic resonance imaging are often utilized.

Melanoma biomarkers are promising factors for identifying patients at risk for melanoma, early detection, confirming diagnosis, monitoring therapies and predicting recurrence. This review reported on current demographic, clinical and pathological features as well as numerous key discoveries regarding serological and molecular biomarkers of malignant melanoma.

\section{Demographic and clinical factors}

Several demographic factors that affect the survival of patients with melanoma have been identified. In a study by White $e t a l$, AJCC stage III melanoma patients $<50$ years of age were found to have a 5-year survival of $48 \%$, while for patients $>50$ years survival was $\sim 38 \%$ (5). Female gender was found 
to be associated with a more favorable prognosis $(6,7)$, while patients with an axial primary tumor had a worse prognosis than those with a peripheral tumor (5). Barth et al (6) found that patients with tumors that required $>72$ months to progress from stage II to stage IV melanoma had a median overall survival of 9.6 months. However, patients with tumors that required $<72$ months had an overall survival of 7.6 months (6). Karakousis et al (9) found that the number of metastases had a considerable effect on the 5-year survival of patients with stage IV melanoma. Patients with one metastasis had a 5-year survival rate of $33 \%$, while those who had $>4$ metastases had a 5-year survival of $13 \%$ (9). It has been demonstrated that sites of metastatic foci appear to impact 5-year survival rates (3). For example, a cutaneous metastasis was associated with the most favorable survival rate of $27 \%$, while lymph node and visceral metastases had survival rates of 15 and $2 \%$, respectively (3).

Therefore, patients with distant metastasis in the skin, subcutaneous tissue or distant lymph nodes are categorized as M1a (3). Such patients have a relatively better prognosis compared to those with metastases located in any other anatomic site $(3,6,8)$. Patients with metastasis to the lung are categorized as M1b and have an intermediate prognosis when 1-year survival rates are compared. Those patients with metastases to any other visceral sites have a relatively worse prognosis and are designated as M1c (3).

Eton et al (10) and Allen et al (11) demonstrated that i) patients bearing tumors with a doubling time of $>60$ days had a 5 -year survival of $20.7 \%$, whereas patients bearing tumors with <60-day doubling time had a $0 \%$ survival; ii) patients who received complete resection of their tumors had a 5-year survival of $24 \%$, while patients who had incomplete resection had $\sim 0 \%$ survival rate; and iii) responders to systemic therapy had a better survival $(10,11)$. In a recent retrospective study, Bedikian et al (12) identified treatment with bio-chemotherapy as one of the favorable prognostic factors that affect long-term survival in patients with advanced melanoma.

\section{Primary tumor characteristics}

For stage I and II melanoma, thickness of the primary tumor is a significant prognostic factor (1). For stage III melanoma, overall 5-year survival rates based on thickness are as follows: thickness <1 mm, 53\%; thickness $1-2 \mathrm{~mm}, 47 \%$; thickness 2-4 mm, 40\%; and 34\% for tumors $>4-\mathrm{mm}$ thick (1). The thickness of the primary tumor was not found to have a significant effect on prognosis after tumor metastasis.

The presence of ulceration, which is defined as the absence of an intact epidermis overlying a significant portion of the primary melanoma based on microscopic examination of the histological sections $(3,13,14)$ of the primary tumor site, is also one of the main prognostic factors for stage III disease. The presence or absence of ulceration is the third most significant prognostic factor in determining the pathological stage (3) in that it independently predicts outcome in stage I, II and III melanoma (3,13-16). Survival among patients with an ulcerated primary tumor is more severe than among those with no ulceration (3).

According to AJCC, the second most significant prognostic factor for patients with nodal metastasis is the tumor burden in the lymph nodes (3). Lymph nodes without clinical or radiologic evidence of metastasis, but with pathological documentation of metastasis are considered to be micrometastases. Those with clinical or radiologic evidence of metastasis are considered macrometastases. For patients with micrometastases, documenting the number of lymph node metastases after lymphadenectomy is important $(3,4,17)$. Survival rates for patients with micrometastases are significantly higher than for those with macrometastases (3).

The number of involved lymph nodes has been a key determinant of survival for stage III melanoma; AJCC used lymph node involvement as the determining criterion for the $\mathrm{N}$ category (3). N1 designates the presence of the involvement of one lymph node, N2, 2-3, while N3 indicates the involvement of four or more lymph nodes (3). According to White et al, the 5-year survival rate declined from $53 \%$ in patients with involvement of one lymph node to $25 \%$ in patients with four or more lymph nodes (5). Furthermore, in patients with lymph nodes positive for metastasis, microscopic vs. macroscopic involvement significantly impacts the survival rates and prognosis in that patients with macroscopic involvement have a worse prognosis than those with microscopic lymph node metastasis.

The presence of lymphocytes infiltrating the primary tumor site was found to have a favorable prognostic effect on the survival of stage III patients since lymphocytes play a role in the immune defense against melanoma. For example, patients with efficient infiltrate had a 40-month disease-free survival of $73 \%$, compared to a 40 -month disease-free survival of $23 \%(18,19)$.

On the other hand, aneuploidy was found to have an unfavorable prognostic effect on the survival of patients (20).

\section{Serological factors}

Lactate dehydrogenase $(L D H)$. $\mathrm{LDH}$ is an enzyme that is present in a wide variety of organisms, including plants and animals. It catalyzes the interconversion of pyruvate and lactate with the concomitant interconversion of NADH and $\mathrm{NAD}^{+}$. It converts pyruvate, the final product of glycolysis, to lactic acid when oxygen is absent or in short supply, and it performs the reverse reaction during the Cori cycle in the liver. It is used for the assessment of tissue breakdown, in general, a process that is possible when there are no other indicators of hemolysis. LDH is used to follow up cancer (especially lymphoma) patients, as cancer cells have a high rate of turnover with destroyed cells leading to an elevated LDH activity. Serum LDH is an independent prognostic factor in patients with stage IV melanoma (21-23). It is the only biomarker that is used by the AJCC staging system of melanoma (3). When serum LDH is elevated above the upper limits of normal at the point of staging, patients with distant metastases are assigned to M1c regardless of the site of their distant metastases (3). Elevated serum LDH should be used only when there are two or more determinations obtained $>24 \mathrm{~h}$ apart (3), since results of a single determination can be falsely positive due to hemolysis or other factors unrelated to melanoma metastases.

$S 100 \beta$. S100 $\beta$ is a low molecular weight dimeric acidic calcium-binding protein. The name is derived from its solubility in $100 \%$ saturated ammonium sulfate at a neutral $\mathrm{pH}(24)$. S100 protein is expressed by a wide range of cells derived from 
the neural crest (Schwann cells, melanocytes and glial cells), chondrocytes, adipocytes, myoepithelial cells, macrophages, Langerhans cells, dendritic cells and keratinocytes. The protein consists of $\alpha$ and $\beta$ subunits, and the form that is found in melanoma is $\alpha \beta$ dimer (24). The $\alpha \beta$ protein is also present in glial, Schwann and Langerhans cells. The serum level of S100 $\beta$ is not specific, as abnormal levels are noted in liver, brain and renal injury along with many inflammatory and infectious processes (25). The $\beta$ subunit is the form related to tumor invasiveness. S100 protein is thought to interact with tumor suppressor p53 protein, thus affecting its function in cellular growth (24). S100 levels are detected in the serum of melanoma patients using immunoassays of monoclonal antibodies directed against the $\beta$ subunit of the protein (24). An increased S100 $\beta$ level is specific to melanoma when brain disease is excluded (26). Patients with the highest level of S100 $\beta$ are those with liver and skeletal muscle metastases (27). Several studies have shown conflicting results. In a recent study of 3,393 patients, $S 100 \beta$ was found to be a prognostic factor independent of the TNM staging system $(25,29)$. In a study of 296 melanoma patients (29), comparisons were made between S100, melanoma inhibitory activity, LDH, alkaline phosphatase (AP) and reverse transcriptase (RTC). S100 sensitivity was found to be $29 \%$, which was higher than all of the above-mentioned biomarkers. The diagnostic accuracy was higher than LDH, AP and RTC. The elevated values of S100 $\beta$ were associated with a decreased survival rate and worse disease (30). Although its sensitivity is low, the prognostic value is high (31). The level of the protein was shown to be related to the stage of melanoma (32-35), the degree of metastasis and disease activity (26), and tumor mass. It has also shown promise in monitoring therapeutic interventions $(34,37,38)$, predicting relapse (28), as well as survival (26-28).

Melanoma inhibitory activity (MIA). MIA is an autocrine growth regulatory factor secreted by melanoma cells. It is strongly expressed by malignant melanoma cells, moderately expressed by nevi and not significantly expressed by normal skin melanocytes, keratinocytes or other skin cells (39-41). It was found to be expressed in cartilage $(42,43)$ and, therefore, mildly elevated in patients with arthritis. MIA was also observed in breast cancer, colon cancer and chondrosarcoma $(43,44)$. The postulated theory is that MIA decreases melanoma cell adhesion to the extracellular matrix and promotes metastasis (40). The MIA gene was assigned to the 19q13 locus by fluorescent in situ hybridization (45) in 1996. Since then, this protein has been extensively studied. ELISA is used to measure the MIA serum levels of melanoma patients (39). MIA was evaluated by several studies as one of the most specific and sensitive biomarkers available for malignant melanoma $(31,39,43)$. The level of MIA in the serum of patients with malignant melanoma was found to correlate with tumor stage. It was also shown to be helpful in detecting the progression from localized to metastatic disease (46) and in monitoring the treatment of melanoma $(39,41)$.

TA90 antigen. TA90 antigen is a $90-\mathrm{kDa}$ tumor-associated antigen that is a free antigen and an IgG-bound immune complex (TA90-IC) in the serum of melanoma patients (47). Patients with stage IV melanoma and extensive tumor burden were found to express high levels of free TA90 and low levels of TA90-IC, whereas patients with early stage disease and low tumor burden rarely had free antigen, but exhibited TA90-IC instead. The expression of the TA90 antigen in nonmelanoma tissues is limited to certain inflammatory states, such as cirrhosis associated with hepatitis (48). ELISA is used to detect TA90-IC in the serum of melanoma patients. Studies have found this marker to be highly prognostic in patients with various stages of melanoma (49). It was found to be highly correlated with an improved 5-year disease-free and overall survival (50). Several analysis studies identified anti-TA90 IgM as an independent prognostic factor for melanoma (50). IgG and IgM antibody titers were found to be the basis for monitoring immune response to polyvalent vaccines. Administration of antibodies may play a significant role in modulating survival in melanoma patients (50). Additionally, elevation in anti-TA90 IgM antibody but not IgG titers was associated with prolonged patient survival (50-52).

Tyrosinase. Tyrosinase is a monoxygenase copper-containing enzyme that catalyzes the oxidation of tyrosine to dopa and then to dopaquinone, and is a specific marker for melanocytes and Schwann cells (53). Melanocytes and Schwann cells do not normally circulate in peripheral blood (54), thus the detection of tyrosinase mRNA in blood is assumed to indicate the presence of metastasis. Reverse transcriptase-polymerase chain reaction (RT-PCR) is used to analyze peripheral blood for tyrosinase mRNA expression. Several studies reported a correlation between tyrosinase RT-PCR and melanoma relapse progression (12,55-57). Positive tyrosinase in peripheral venous blood was found to be statistically significant and, more importantly, an independent negative predictor of survival $(12,55)$. RT-PCR for tyrosinase mRNA was found to be a significant prognostic factor for progression-free and overall survival in melanoma (12).

Melanoma antigen gene A3 protein (MAGE-A3). MAGE-A3 is a member of the MAGE-A family. This family encodes proteins with a $50-80 \%$ identity to each other. The variability resides in the promoters and the first exon, indicating that this family plays the same role that is expressed under different transcriptional controls. The family is expressed by chromosomal location Xq28.

The genes are silent in normal cells, except male germline cells. However, the genes are expressed in melanoma, as well as in various other tumors $(58,59)$. MAGE-A3 protein is detected in the blood using RT-PCR. Elevated blood levels of MAGE-A3 protein were found to be associated with early stages of melanoma (58). However, Reynolds et al found that MAGE-A3 is not an independent prognostic factor for melanoma (60).

Glycoprotein $Y K L-40$. Glycoprotein YKL-40, also known as Chondrex or Chitinase 3-like (CHI3L1), cartilage glycoprotein-39 or chondrocyte protein YKL-40, is secreted by a wide range of cells, including articular chondrocytes, synovial cells, macrophages and mature neutrophils. High levels of YKL-40 were found in synovial fluid from patients with active rheumatoid arthritis (RA) and in the hippocampus of schizophrenic patients. YKL-40 belongs to the 18-glycosyl hydrolase 
(mammalian chitinase), and the term YKL represents its $\mathrm{N}$-terminal tripeptide sequence. YKL-40 is thought to play a role in the migration of endothelial cells and/or formation of branching tubules that promote angiogenesis $(61,62)$. Serum levels are determined using ELISA. Although the serum level is neither specific nor sensitive, it was correlated with the stage of melanoma (63) and poor survival (61).

Cytoplasmic melanoma-associated antigen (CYT-MAA). CYT-MAA is a cytoplasmic protein comprising four polypeptides and is synthesized by many tumor and normal cells. This protein was found in melanoma at higher levels than in normal cells (64). The protein is neither sensitive nor specific, and does not correlate with the stage of melanoma. However, it was linked to disease recurrence and progression $(64,65)$. Serum levels are measured using double-sandwich ELISA. Reynolds et al conducted the first study to measure CYT-MAA levels in melanoma patients receiving immunotherapy (65). The results indicated that it is a potential marker that can be used to monitor response to immunotherapy.

Melanotransferrin (MTF). MTF or melanoma-associated tumor antigen p97 is a membrane-bound glycoprotein that is a homolog of the transferrin (Tf) family of non-heme Fe-binding proteins (66). It is expressed in normal adult tissues (67), fetal tissues, as well as in various tumor cells (68). A larger amount of MTF is expressed in the salivary glands, pancreas and epididymis at the tissue level (70). The exact function of MTF in melanoma has yet to be elucidated. However, MTF was implicated in a diverse range of biological processes, and emerging data indicate that it plays a role in angiogenesis (70,71), cellular proliferation (72) and tumorigenesis. MTF is detected in the blood using RT-PCR. The test, however, lacks both specificity and sensitivity.

Microphthalmia-associated transcription factor (MITF). MITF is a basic helix-loop-helix leucine zipper transcription factor for tyrosinase and tyrosinase-related proteins. It plays a critical role in the differentiation and development of melanocytes and osteoclasts (73). MITF is implicated in the proliferation of malignant melanoma (74). Two methods of detection have been identified against MITF, including RT-PCR (reverse transcriptase-PCR) and monoclonal antibody. MITF detection after melanoma treatment was shown to be an independent prognostic factor for patient survival (75). MITF indicates subclinical metastatic disease and predicts treatment outcome in melanoma patients (75). Its concentration was also found to correlate with the stage of melanoma (76).

Glycoprotein 100 (gp100). gp100, also known as SILV, ME20 or Pmel17, is a $100-\mathrm{kDa}$ type I transmembrane protein. The processing of this protein results in the formation of melanosomal striation (77). This protein is expressed at low levels in adult melanocytes, but is overexpressed by proliferating neonatal melanocytes and in melanoma. The protein is present in the membranous form, ME20-M, which secretes a soluble glycoprotein, ME20-S. The latter protects melanoma cells from antibody-mediated immunity (77). gp100 is determined using monoclonal antibody HMB-45. The expression of gp100 varies within the tumor and between patients (78).
No correlation was found between the expression of gp100 and responsiveness to immunotherapy (78). Furthermore, the protein lacked specificity (79).

$C$-reactive protein $(C R P)$. CRP is a protein synthesized by hepatocytes in response to cytokines, such as interleukin (IL)-6, IL-1 and tumor necrosis factor $\alpha(80,81)$. This protein is produced as a non-specific acute phase response to almost all forms of inflammation (80). In a study of melanoma, CRP was assayed in human blood using an immunonephelometric technique on a protein system analyzer (82). Elevated serum CRP levels along with IL-6 were associated with reduced survival in metastatic melanoma and resistance to IL-2 therapy (82-86). CRP was found to be an independent prognostic factor for survival (86). In one study, CRP was found to be superior to $\mathrm{LDH}$ in discriminating melanoma patients entering AJCC stage IV from patients remaining in AJCC stages I, II or III (82). CRP was detected with a sensitivity of $77 \%$ and specificity of $90 \%$ in determining the progression of disease into stage IV (82).

\section{Circulating tumor cells}

Circulating tumor cells (CTCs) are defined as the leukemic phase of solid tumors and are required for the establishment of distant metastasis for a certain cancer type (87). In this model of metastasis, CTCs migrate from the tumor site, travel through lymphatics and blood, form micrometastases at distant organ sites and ultimately lead to overt metastatic disease (87). For patients with stage II and III melanoma, Mocellini et al showed that the detection of CTCs in peripheral blood is used to predict tumor relapse, assess treatment failure and select patients for adjuvant therapy (88). However, conflicting evidence exists in the literature regarding the correlation between CTC detection, stage of disease and clinical outcomes in melanoma. The discovery of melanoma CTCs in peripheral blood has been widely inferred, with the RT-PCR demonstration of tyrosinase and MAGE-A3 mRNA markers thus far $(88,89)$. This method is limited by falsepositive and false-negative results and low reproducibility (87). Discrepancies in results are influenced by genomic instability of melanoma cells, discontinuous shedding of CTCs into the bloodstream and the low numbers of CTCs compared to normal blood components (87). Alternative detection methods are essential for the ultimate use of CTCs in the clinical setting. Promising techniques that provide genetic and molecular characterization of tumor metastases include transcriptional studies, comparative genomic hybridization and single nucleotide polymorphism genotyping (87). Ulmer et al described the detection of intact circulating melanoma cells by immunomagnetic cell sorting with subsequent genomic analysis (89). The statistical significance found between the detection of CTCs and tumor stage is promising for the elucidation of the molecular-genetic basis of the establishment of malignant melanoma (80).

\section{Current practice}

Current management of advanced stage melanoma does not involve the use of molecular biomarkers to assess tumor 
response to cytotoxic or immune-modulating chemotherapy. Clinical history, physical examination, pathology and various imaging modalities are presently used to gauge disease progression. Serum LDH levels, although used as an independent prognostic factor, are not explicitly employed to assess response to treatment (3). Pre-treatment serum LDH is used as a significant predictor of survival (90). It remains unclear whether change in serum LDH during treatment of advanced disease is associated with survival (91). This review has identified several experimental biomarkers as potential indicators of disease progression, treatment response and recurrence. The data warrant further investigation into the detection of tyrosinase mRNA during interferon therapy as a marker of therapeutic response (92). An analysis of additional serum melanogenic markers pre- and post-therapy may potentially be used to guide treatment.

\section{Conclusion}

The AJCC staging system lays the present framework for determining the stage and prognosis of malignant melanoma using various clinical and pathological biomarkers. The only molecular biomarker presently included is LDH. Several studies involving other molecular markers have been conducted and various markers have been identified as useful future methods for the detection and evaluation of therapeutic response and risk of metastasis. Despite these advances, a specific molecular marker or method of detection has yet to be applied to the clinical management of melanoma patients. Studies confirming these biomarkers as valuable prognostic factors require validation using more specific and sensitive detection methods, as well as large-scale patient cohorts. Forging ahead with studies that combine the use of different biomarkers is essential in the identification of a valuable long-awaited method that can aid in the prediction of prognosis, therapeutic response and risk of metastasis in patients with malignant melanoma.

\section{References}

1. Biomarkers Definitions Working group: Biomarkers and surrogate end points: preferred definitions and conceptual framework. Clin Pharmacol Ther 69: 89-95, 2001.

2. Beastall GH, Cook B, Rustin GJS and Jennings J: A review of the role of established tumor markers. Ann Clin Biochem 28: $5-18,1991$.

3. Balch CM, Buzaid AC, Soong SJ, et al: Final version of the American Joint Committee on Cancer staging system for cutaneous melanoma. J Clin Oncol 19: 3635-3648, 2001.

4. Gershenwald JE, Thompson W, Mansfield PF, et al: Multiinstitutional melanoma lymphatic mapping experience: the prognostic value of sentinel lymph node status in 612 stage I or II melanoma patients. J Clin Oncol 17: 976-983, 1999.

5. White RR, Stanley WE, Johnson JL, Tyler DS and Seigler HF: Long-term survival in 2,505 patients with melanoma with regional lymph node metastasis. Ann Surg 235: 879-887, 2002.

6. Barth A, Wanek LA and Morton DL: Prognostic factors in 1,521 melanoma patients with distant metastases. J Am Coll Surg 181: 193-201, 1995.

7. Manola J, Atkins M, Ibrahim J, et al: Prognostic factors in metastatic melanoma: a pooled analysis of Eastern Cooperative Oncology Group trials. J Clin Oncol 18: 3782-3793, 2000.

8. Bowen GM, Chang AE, Lowe L, et al: Solitary melanoma confined to the dermal and/or subcutaneous tissue: evidence for revisiting the staging classification. Arch Dermatol 136: 1397-1399, 2000.

9. Karakousis CP, Velez A, Driscoll DL and Takia H: Mastectomy in malignant melanoma. Surgery 115: 295-302, 1994.
10. Eton O, Legha SS, Moon TE, et al: Prognostic factors for survival of patients treated systemically for disseminated melanoma. J Clin Oncol 16: 1103-1111, 1998.

11. Allen IE, Kupelnick B, Kumashiro M, et al: Efficacy of interleukin-2 in the treatment of metastatic melanoma: systematic review and meta-analysis. Cancer Ther 1: 168-173, 1998.

12. Bedikian AY, Johnson MM, Warneke CL, et al: Prognostic factors that determine the long-term survival of patients with unresectable metastatic melanoma. Cancer Invest 26: 624-633, 2008.

13. Balch CM, Wilkerson JA, Murad TM, et al: The prognostic significance of ulceration of cutaneous melanoma. Cancer 45: 3012-3017, 1980.

14. McGovern VJ, Shaw HM, Milton GW, et al: Ulceration and prognosis in cutaneous malignant melanoma. Histopathology 6: 399-407, 1982.

15. Balch CM, Soong SJ, Gershenwald JE, et al: Prognostic factor analysis of 17,600 melanoma patients: validation of the American Joint Committee on Cancer melanoma staging system. J Clin Oncol 19: 3622-3634, 2001.

16. Buzaid AC, Ross MI, Balch CM, et al: Critical analysis of the current American Joint Committee on Cancer staging system for cutaneous melanoma and proposal of a new staging system. J Clin Oncol 15: 1039-1051, 1997.

17. Cascinelli N, Belli F, Santinami M, et al: Sentinel lymph node biopsy in cutaneous melanoma: the WHO Melanoma Program experience. Ann Surg Oncol 7: 469-474, 2000.

18. Clemente CG, Mihm MC Jr, Bufalino R, Zurrida S, Collini P and Cascinelli N: Prognostic value of tumor infiltrating lymphocytes in vertical growth phase of primary cutaneous melanoma. Cancer 77: 1303-1310, 1996.

19. Mihm MC Jr, Clemente CG and Cascinelli N: Tumor infiltrating lymphoctyes in lymph node mlelanoma metastases: a histopathologic prognostic indicator and an expression of local immune response. Lab Invest 74: 43-47, 1996.

20. Healy E, Belgaid C, Takata M, et al: Prognostic significance of allelic losses in primary melanoma. Oncogene 16: 2213-2218, 1998.

21. Brochez L and Naeyaert JM: Serological markers for melanoma. Br J Dermatol 143: 256-268, 2000.

22. Sirott MN, Bajorin DF, Wong GY, et al: Prognostic factors in patients with metastatic malignant melanoma: a multivariate analysis. Cancer 72: 3091-3098, 1993.

23. Finck SJ, Giuliano AE and Morton DL: LDH and melanoma. Cancer 51: 840-843, 1983.

24. JaĖckel A, Deichman M, Waldmann V, et al: S-100b protein in serum, a tumor marker in malignant melanoma current state of knowledge and clinical experiences. Hautarzt 50: 250-256, 1999.

25. Molina R, Navarro J, Filella X, Castel T and Ballesta AM: S-100 protein serum levels in patients with benign and malignant diseases: false-positive results related to liver and renal function. Tumour Biol 23: 39-44, 2002.

26. Hauschild A, Michaelsen J, Brenner W, et al: Prognostic significance of serum S100B detection compared with routine blood parameters in advanced metastatic melanoma patients. Melanoma Res 9: 155-161, 1999.

27. Hauschild A, Engel G, Brenner W, et al: S100B protein detection in serum is a significant prognostic factor in metastatic melanoma. Oncology 56: 338-344, 1999.

28. Bonfrer JMG, Korse CM and Israels SP: Serum S-100 has prognostic significance in malignant melanoma. Anticancer Res 17: 2975-2978, 1997.

29. Mocellin S, Zavagno G and Nitti D: The prognostic value of serum S100B in patients with cutaneous melanoma: a metaanalysis. Int J Cancer 123: 2370-2376, 2008.

30. Garbe C, Leiter U, Ellwanger U, et al: Diagnostic value and prognostic significance of protein S-100beta, melanoma-inhibitory activity and tyrosinase/MART-1 reverse transcription-polymerase chain reaction in the follow-up of high-risk melanoma patients. Cancer 97: 1737-1745, 2003.

31. Medic S, Pearce RL, Heenan PJ and Ziman M: Molecular markers of circulating melanoma cells. Pigment Cell Res 20: 80-91, 2007.

32. Kaskel P, Berking C, Sander S, et al: S-100 protein in peripheral blood: a marker for melanoma metastases. J Am Acad Dermatol 41: 962-969, 1999.

33. Von Schoultz E, Hansson LO, Djureen E, et al: Prognostic value of serum analyses of S-100 beta protein in malignant melanoma. Melanoma Res 6: 133-137, 1996. 
34. Guo HB, Stoffel-Wagner B, Bierwirth T, Mezger $J$ and Klingmuller D: Clinical significance of serum S 100 in metastatic malignant melanoma. Eur J Cancer 31: 1898-1902, 1995.

35. Kärnell R, von Schoultz E, Hansson LO, Nilsson B, Arstrand K and Kagedal B: S 100B protein, 5-S-cysteinyldopa and 6-hydroxy5-methoxyindole-2-carboxylic acid as biochemical markers for survival prognosis in patients with malignant melanoma. Melanoma Res 7: 393-399, 1997.

36. Henze G, Dummer R, Joller-Jemelka HI, Boni R and Burg G: Serum S 100-a marker for disease monitoring in metastatic melanoma. Dermatology 194: 208-212, 1997.

37. Krähn G, Kaskel P, Sander S, et al: S 100 beta is a more reliable tumor marker in peripheral blood for patients with newly occurred melanoma metastases compared with MIA, albumin and lactate-dehydrogenase. Anticancer Res 21: 1311-1316, 2001.

38. Hauschild A, Engel G, Brenner W, et al: Predictive value of serum $\mathrm{S} 100 \mathrm{~B}$ for monitoring patients with metastatic melanoma during chemotherapy and/or immunotherapy. Br J Dermatol 140: 1065-1071, 1999.

39. Bosserhoff AK, Kaufmann M, Kaluza B, et al: Melanoma inhibiting activity, a novel serum marker for progression of malignant melanoma. Cancer Res 57: 3149-3153, 1997.

40. Bosserhoff AK, Hein R, Bogdahn U, et al: Structure and promoter analysis of the gene encoding the human melanomainhibiting protein MIA. J Biol Chem 271: 490-495, 1996.

41. Bosserhoff AK, Dreau D, Hein R, et al: Melanoma inhibitory activity (MIA), a serological marker of malignant melanoma. Recent Results Cancer Res 158: 158-168, 2001.

42. Dietz UH and Sandell LJ: Cloning of a retinoic acid-sensitive mRNA expressed in cartilage and during chondrogenesis. J Biol Chem 271: 3311-3316, 1996.

43. Bosserhoff $\mathrm{AK}$ and Buettner R: Expression, function and clinical relevance of MIA (melanoma inhibitory activity). Histol Histopathol 17: 289-300, 2002.

44. Bosserhoff AK, Moser M, Hein R, et al: In situ expression patterns of melanoma-inhibiting activity (MIA) in melanomas and breast cancers. J Pathol 187: 446-454, 1999.

45. Koehler MR, Bosserhoff A, von Beust G, Bauer A, Blesch A, Buettner R, Schlegel J, Bogdahn U and Schmid M: Assignment of the human melanoma inhibitory activity gene (MIA) to 19q13.4 by fluorescence in situ hybridization (FISH). Genomics 35: 264-267, 1996.

46. Bosserhoff AK, Lederer M, Kaufmann M, et al: MIA, a novel serum marker for progression of malignant melanoma. Anticancer Res 19: 2691-2693, 1999.

47. Kelley MC, Gupta RK, Hsueh EC, Yee R, Stern S and Morton DL: Tumor associated antigen TA90 immune complex assay predicts recurrence and survival after surgical treatment of stage I-III melanoma. J Clin Oncol 19: 1176-1182, 2001

48. Faries MB, Gupta RK, Ye X, et al: A comparison of 3 tumor markers (MIA, TA90IC, S100B) in stage III melanoma patients. Cancer Invest 25: 285-293, 2007.

49. Tsioulias G, Gupta RK, Tisman G, et al: Serum TA90 antigenantibody complex as a surrogate marker of the efficacy of a polyvalent allogeneic whole-cell vaccine (Cancer-Vax) in melanoma. Ann Surg Oncol 8: 198-203, 2001.

50. DiFronzo L, Gupta RK, Essner R, et al: Enhanced humoral immune response correlates with improved disease-free and overall survival in American Joint Committee on Cancer stage II melanoma patients receiving adjuvant polyvalent vaccine. J Clin Oncol 20: 3242, 2002

51. Jones RC, Kelley MC, Gupta RK, et al: Immune response to polyvalent melanoma cell vaccine in AJCC stage III melanoma: an immunologic survival model. Ann Surg Oncol 3: 437-445, 1996.

52. Chung M, Gupta RK, Hsueh E, et al: Humoral immune response to a therapeutic polyvalent cancer vaccine after complete resection of thick primary melanoma and sentinel lymphadenectomy. J Clin Oncol 21: 313-319, 2003.

53. Kunter U, Buer J, Probst M, et al: Peripheral blood tyrosinase messenger RNA detection and survival in malignant melanoma. J Natl Cancer Inst 88: 590-594, 1996.

54. Smith B, Selby P, Southgate J, et al: Detection of melanoma cells in peripheral blood by means of reverse transcriptase and polymerase chain reaction. Lancet 338: 1227-1229, 1991.

55. Mellado B, Gutierrez L, Castel T, et al: Prognostic significance of the detection of circulating malignant cells by reverse transcriptase-polymerase chain reaction in long-term clinically disease-free melanoma patients. Clin Cancer Res 5: 1843-1848, 1999.
56. Mellado B, Colomer D, Castel T, et al: Detection of circulating neoplastic cells by reverse-transcriptase polymerase chain reaction in malignant melanoma: association with clinical stage and prognosis. J Clin Oncol 14: 2091-2097, 1996.

57. Schittek B, Bodingbauer Y, Ellwanger U, et al: Amplification of MelanA messenger RNA in addition to tyrosinase increases sensitivity of melanoma cell detection in peripheral blood and is associated with the clinical stage and prognosis of melanoma. $\mathrm{Br}$ J Dermatol 141: 30-36, 1999.

58. Koyanagi K, Kuo C, Nakagawa T, Mori T, Ueno H, Lorico AR Jr, Wang HJ, Hseuh E, O'Day SJ and Hoon DS: Multimarker quantitative real-time PCR detection of circulating melanoma cells in peripheral blood: relation to disease stage in melanoma patients. Clin Chem 51: 981-988, 2005.

59. Matsuzaki Y, Hashimoto S, Fujita T, Suzuki T, Sakurai T, Matsushima K and Kawakami Y: Systematic identification of human melanoma antigens using serial analysis of gene expression (sage). J Immunother 28: 10-19, 2005.

60. Reynolds SR, Albrecht J, Shapiro RL, Roses DF, Harris MN, Conrad A, Zeleniuch-Jacquotte A and Bystryn JC: Changes in the presence of multiple markers of circulating melanoma cells correlate with clinical outcome in patients with melanoma. Clin Cancer Res 9: 1497-1502, 2003.

61. Schmidt H, Johansen JS, Gehl J, Geertsen PF, Fode K and der Maase H: Elevated serum level of ykl-40 is an independent prognostic factor for poor survival in patients with metastatic melanoma. Cancer 106: 1130-1139, 2006.

62. Malinda KM, Ponce L, Kleinman HK, Shackelton LM and Millis AJ: Gp38k, a protein synthesized by vascular smooth muscle cells, stimulates directional migration of human umbilical vein endothelial cells. Exp Cell Res 250: 168-173, 1999.

63. Schmidt H, Johansen JS, Sjoegren P, et al: Serum YKL-40 predicts relapse-free and overall survival in patients with American Joint Committee on Cancer stage I and II melanoma. J Clin Oncol 24: 798-804, 2006.

64. Vergilis IJ, Szarek M, Ferrone S and Reynolds SR: Presence and prognostic significance of melanoma-associated antigens Cyt-Maa and Hmw-Maa in serum of patients with melanoma. J Invest Dermatol 125: 526-531, 2005.

65. Reynolds SR, Vergilis IJ, Szarek M, Ferrone S and Bystryn J: Cytoplasmic melanoma-associated antigen (CYT-MAA) serum level in patients with melanoma: a potential marker of response to immunotherapy? Int J Cancer 119: 157-161, 2006.

66. Brown JP, Hewick RM, Hellstrom I, Hellstrom KE, Doolittle RF and Dreyer WJ: Human melanoma associated antigen p97 is structurally and functionally related to transferrin. Nature 296: 171-173, 1982.

67. Richardson DR: The role of the membrane-bound tumour antigen, melanotransferrin (p97), in iron uptake by the human malignant melanoma cell. Eur J Biochem 267: 1290-1298, 2000.

68. Brown JP, Nishiyama K, Hellstrom I and Hellstrom KE: Structural characterization of human melanoma-ssociated antigen p97 with monoclonal antibodies. J Immunol 127: 539-546, 1981

69. Sekyere EO, Dunn LL and Richardson DR: Examination of the distribution of the transferrin homologue, melanotransferrin (tumour antigen p97), in mouse and human. Biochim Biophys Acta 1722: 131-142, 2005.

70. Graeven U, Rodeck U, Karpinski S, Jost M, Philippou S and Schmiegel W: Modulation of angiogenesis and tumorigenicity of human melanocytic cells by vascular endothelial growth factor and basic fibroblast growth factor. Cancer Res 61: 7282-7290, 2001.

71. Sala R, Jefferies WA, Walker B, et al: The human melanoma associated protein melanotransferrin promotes endothelial cell migration and angiogenesis in vivo. Eur J Cell Biol 81: 599-607, 2002.

72. Dunn LL, Sekyere EO, Suryo Rahmanto Y and Richardson DR The function of melanotransferrin: a role in melanoma cell proliferation and tumorigenesis. Carcinogenesis 27: 2157-2169, 2006.

73. Levy C, Khaled M and Fisher DE: MITF: master regulator of melanocyte development and melanoma oncogene. Trends Mol Med 12: 406-414, 2000.

74. Garraway LA, Widlund HR, Rubin MA, et al: Integrative genomic analyses identify MITF as a lineage survival oncogene amplified in malignant melanoma. Nature 436: 117-122, 2005. 
75. Koyanagi K, O'Day SJ, Gonzalez R, et al: Microphthalmia transcription factor as a molecular marker for circulating tumor cell detection in blood of melanoma patients. Clin Cancer Res 12: 1137-1143, 2006.

76. Hoek KS, Schlegel NC, Bradfford P, et al: Metastatic potential of melanomas defined by specific gene expression profiles with no B-RAF signature. Pigment Cell Res 19: 290-302, 2006.

77. Maresh GA, Marken JS, Neubauer M, et al: Cloning and expression of the gene for the melanoma-associated ME20 antigen. DNA Cell Biol 13: 87-95, 1994.

78. Scheibenbogen C, Weyers I, Ruiter D, et al: Expression of gp100 in melanoma metastases resected before or after treatment with IFN alpha and IL-2. J Immunother Emphasis Tumor Immunol 19: 375-380, 1996.

79. Schrader AJ, Probst-Kepper M, Grosse J, Kunter U, Schenk F, Franzke A, Atzpodien J and Buer J: Molecular and prognostic classification of advanced melanoma: a multi-marker microcontamination assay of peripheral blood stem cells. Melanoma Res 10: 355-362, 2000

80. Mahmoud FA and Rivera NI: The role of C-reactive protein as a prognostic indicator in advanced cancer. Curr Oncol Rep 4 $250-255,2002$.

81. Castell JV, Gómez-Lechón MJ, David M, Andus T, Geiger T, Trullenque R, Fabra R and Heinrich PC: Interleukin-6 is the major regulator of acute phase protein synthesis in adult human hepatocytes. FEBS Lett 242: 237-239, 1989.

82. Deichmann M, Kahle B, Moser K, Wacker J and Wu K: Diagnosing melanoma patients entering American Joint Committee on Cancer stage IV, C-reactive protein in serum is superior to lactate dehydrogenase. Br J Cancer 91: 699-702, 2004.

83. Mouawad R, Benhammouda A, Antoine EC, Borel C, Weil M, Khayat D and Soubrane C: Endogenous interleukin 6 levels in patients with metastatic malignant melanoma: correlation with tumor burden. Clin Cancer Res 2: 1405-1409, 1996.

84. Tartour E, Dorval T, Mosseri V, Deneux L, Mathiot C, Brailly H, Montero F, Joyeux I, Pouillart P and Fridman WH: Serum interleukin 6 and C-reactive protein levels correlate with resistance to IL-2 therapy and poor survival in melanoma patients. Br J Cancer 69: 911-913, 1994
85. Deichmann M, Benner A, Jackel A, Bock M, Waldmann V and Naher H: Elevated interleukin-6 serum levels indicate progressive disease in metastasized malignant melanoma. J Exp Clin Cancer Res 19: 301-307, 2000.

86. Tartour, E, Blay JY, Dorval T, Escudier B, Mosseri V and Douillard JY: Predictors of clinical response to interleukin2-based immunotherapy in melanoma patients: a French multiinstitutional study. J Clin Oncol 14: 1697-1703, 1996.

87. Jacob K, Sollier C and Jabado N: Circulating tumor cells: detection, molecular profiling and future prospects. Expert Rev Proteonomics 4: 741-756, 2007.

88. Mocellini S, Del Fiore P, Guarnieri L, et al: Molecular detection of circulating tumor cells is an independent prognostic factor in patients with high-risk cutaneous melanoma. Int J Cancer 111: 741-745, 2004.

89. Ulmer A, Schmidt-Kittler O, Fischer J, Ellwanger U, Rassner G, Riethmüller G, Fierlbeck G and Klein CA: Immunomagnetic enrichment, genomic characterization and prognostic impact of circulating melanoma cells. Clin Cancer Res 10: 531-537, 2004.

90. Keilholz U, Martus P, Punt CJ, et al: Prognostic factors for survival and factors associated with long-term remission in patients with advanced melanoma receiving cytokine-based treatments: Second analysis of a randomized EORTC Melanoma Group trial comparing interferon-2a and interleukin-2 (IL-2) with or without cisplatin. Eur J Cancer 38: 1501-1511, 2002.

91. Linette GP, Carlson JA, Slominski A, Mihm MC and Ross JS: Biomarkers in melanoma: stage III and IV disease. Expert Rev Mol Design 5: 65-74, 2005

92. Mellado B, Del Carmen V, Colomer D, et al: Tyrosinase mRNA in blood of patients with melanoma treated with adjuvant interferon. J Clin Oncol 20: 4032-4039, 2002. 